\title{
https://doi.org/10.48009/1_iis_2005_147-155 \\ AN EXPLORATORY LOOK AT STUDENTS' PERCEPTIONS OF BLENDED LEARNING
}

\author{
Karl L. Smart, Central Michigan University, karl.smart@ cmich.edu \\ James J. Cappel, Central Michigan University, james.cappel@cmich.edu
}

\begin{abstract}
In recent years, blended learning, a pedagogical approach that combines online and traditional classroom components, has expanded significantly in the business and educational communities. Although this approach, enabled by technologies such as the Internet, seems to offer many benefits to learners and organizations, few studies to date have evaluated its effectiveness. This investigation examines the use of blended learning in a required undergraduate course where students completed online learning modules prior to class discussion of these units. The study generated mixed results. Although some subjects recognized important benefits to the online modules, the success of this effort appears to be limited by two factors: (1) the time required for the online units was viewed as excessive by many participants for the course; and (2) few participants had prior experience completing online units. The outcomes suggest that students might respond more favorably to blended learning when instructors use smaller segments of online units rather than entire units that take several hours to complete.
\end{abstract}

Keywords: Blended Learning, e-learning, online learning, learner satisfaction

\section{INTRODUCTION}

In trying to find more effective methods of teaching in an era of growing accountability in education, blended learning has emerged as a strategy many schools have adopted or are considering. Blended learning is a hybrid approach that combines elements of e-learning with the traditional classroom environment [14]. E-learning may include most any instruction delivered electronically via the Internet, Intranets, or platforms such as CD-ROM or DVD, with many people referring to "e-learning," "online learning," and "web-based learning" interchangeably [8]. In recent years, universities have increased their resources devoted to e-learning to appeal to audiences such as working adults who might not otherwise have access to higher education [5]. Curricular and organizational changes have also demanded new ways of delivering education to individuals [8].

Although both e-learning and blended learning are growing, they are still at an early stage of development. Consequently, an improved understanding of how students perceive and react to elements of e-learning will help in its effective implementation. This research assesses the perceived effectiveness of blended learning in a required undergraduate business information systems course. The results raise important considerations about using blended learning for business and IS instruction.

\section{LITERATURE REVIEW}

E-learning has the possibility of providing many benefits, such as providing flexibility and convenience to learners while potentially reducing costs. Furthermore, e-learning has 
pedagogical opportunities beyond traditional teaching methods. For instance, multimedia capabilities can be used with learning exercises that allow learners to apply concepts realistically. When used as part of a blended learning approach, e-learning can deliver "new" information not contained in other sources as well as more effectively reinforcing other course information through offering examples, explanations, assessments, and exercises. However, there are also potential downsides to online learning. Among the potential problems with e-learning are a sense of learner isolation; learner frustration, anxiety, and confusion; higher student attrition rates; the need for greater discipline; lack of self-motivation; and the need for online users to make a time commitment to learning $[4,9]$.

Based on these considerations, some research has stressed the importance of using a "blended learning" approach [2], with clearly stated learning objectives and a selection of the best combination of delivery methods to meet those objectives [14]. Although some research has been conducted to examine the effectiveness of e-learning [8], specific research has not addressed the element of learner satisfaction. As the use of e-learning expands in education and business, we must gain an improved understanding of the circumstances in which blended learning can be most effective, leading to the research question: Does blended learning lead to positive learning outcomes as measured by participants' perceptions? The outcomes considered for this measure include user satisfaction and participants' views of various other aspects of the e-learning environment.

As research suggests, learner motivation is one of the key factors affecting student performance and learning, particularly online learning success [1]. If students perceive some benefit to their learning (through either a personal interest in or an application of content), they will likely be more motivated to perform well. As exploratory research, this study is interested in assessing students' attitudes about learning modules used in a course required by IS majors.

\section{METHODOLOGY}

The data for this study are based on students' experiences taking short online courses offered free by the Information Technology Training Initiative (ITTI) of the Michigan Virtual University (MVU), which was integrated into a traditionally taught course. The online courses offered by the ITTI, referred to as "learning units" in this paper, were developed by NETg, a leading vendor of online training products. The courses provide hands-on learning experiences, and include the use of graphics, sound, video, and simulations. Each course is divided into several modules. At the end of each module, students take a mastery test to track their progress and reinforce their understanding of the skills covered. Each online learning unit is designed to be the equivalent of about four to six hours of classroom training.

For this study, students were enrolled in a required course (BIS 360 Business Communications). In the course, student teams were organized at the beginning of the semester and maintained for the duration of the course. The instructor made team assignments based on gender, class ranking, and a short content assessment in an attempt to create heterogeneous groups. Research-based guidelines for creating optimal teams were followed $[3,13]$. The teams frequently engaged in content-related discussions and completed a variety of short tasks as a group. In addition, the teams completed three group exams and a major group project during the semester. 
During the initial two weeks of the course, part of the instruction included exploring group processes and establishing team expectations. Class time was spent addressing the stages of team development (i.e., forming, storming, norming, performing) along with getting acquainted activities to promote team cohesion. The focus on communication emphasizes the critical role of communication in IS curriculum and, subsequently, in the workplace [7]. Half-way through the semester, the class was assigned to complete two ITTI learning units entitled "Team Management: High Performance Teams" and "Virtual Teams: Communicating Effectively."

The purpose of these two learning units was to review principles of effective teams at a point in the semester after group members had gained experience working with one another and had typically encountered some behavioral and communication challenges. In addition, the learning units covered new information not previously addressed in class about virtual teams, conflict in teams, and effective communication. This new content was targeted to prepare students for the major team project in which virtual communication tools (both synchronous and asynchronous) would be widely used.

The e-learning units each consisted of a few carefully focused objectives presented in shorter modules. Each objective was developed with instructional material, including multimedia supported text. Typically, each objective was presented with a series of screens containing information as text and graphics. An accompanying audio track was included that repeated the text for those wishing to listen to the narrative in addition to reading the text. Short video-clips demonstrating certain principles in real-life settings were also integrated. At the end of each module, students were required to take a short multiple-choice online assessment to evaluate their understanding of key concepts within the module. This evaluation was saved and later printed as verification of a student's completing the learning unit.

In addition, each learning unit ended with a simulation, a scenario based on a real-life work situation. For example, the simulation following the Team Management module consisted of video replicating a meeting of a work team consisting of three individuals. A problem was posed to the work team, of which the student was to consider him or herself a part of. Short video clips presented the scenario that demonstrated members of the team responding to issues. Then, the student who was completing the simulation was posed with a series of different responses or actions to take in response to the scenario. From the alternatives, students had to select a response they thought would be appropriate when dealing with issues presented in the video. Depending upon the action students selected, the simulation would progress. The students' choices would resolve problems if the choice was appropriate or cause additional problems if inappropriate (based upon the principles covered in the learning unit), with the continuation of the scenario reflecting the choice of the student.

Various issues—such as motivating the team, dealing with conflict, summarizing issues, or striving for agreement-were covered in the simulations. At the end of the simulation, students were provided with a summary of the decisions they made, detailing the issue presented and the result of their decisions. If potentially better decisions could have been made, these decisions with their expected consequences were also reviewed. 
Students were given the equivalent of two full class sessions (approximately four hours) and no additional homework to work through the learning units during a two-week period. In the session prior to the work sessions, students were guided through registering at the MVU site and shown how to access the learning units. A follow-up interactive exercise and discussion reviewing content from the learning units was held in each class on the due date for completing the learning units. Students took about five minutes to individually write about what they learned in the units. The participants then paired up with a fellow class member for a few minutes to share their responses. Afterwards, the main points of the learning units were reviewed through discussion with the entire class, with an emphasis of how concepts had applied or could apply to the teams students were now a part of in the class. At the end of the session, students submitted a printed summary of their learning unit assessments and their responses to the in-class exercise; those students who submitted this material were given full credit for the assignment.

A survey was administered to students anonymously during the first class meeting after class discussion of the online learning units. The survey instructed participants to provide honest feedback about their experiences with this learning approach. Thirty six of forty students in the course (90 percent) completed the survey. Two open-ended survey questions were also included to solicit respondents' opinions about the online courses' strengths and limitations, and recommendations for improvement. The overall sample was evenly distributed by gender (50 percent females and 50 percent males). The participants consisted of 47 percent seniors, 50 percent juniors, and 3 percent sophomores.

\section{RESULTS}

Most survey questions focus on subjects' perceptions of the online units, since, as noted earlier, the use of e-learning is the main distinguishing feature of blended learning compared to traditional learning, and we were interested in students' perceptions and satisfaction with the elearning components. Table 1 presents the measures of participants' reactions to completing the online learning units, based on a seven-point scale.

Table 1. Students' Perceptions of the Online Learning Units

\begin{tabular}{lcc} 
Survey Question & Mean & SD \\
\hline Overall satisfaction with the learning units \# & 4.25 & 1.42 \\
Using the online units was an effective in learning about assigned topics & 4.68 & 1.53 \\
Using the online learning units was fun & 2.59 & 1.42 \\
A similar online assignment should be used in this course in the future & 3.41 & 1.40 \\
The online units did not take more time and effort than it was worth (rc) & 2.18 & 1.27 \\
Questions asked in the online units were not too difficult (rc) & 5.12 & 1.04
\end{tabular}

\# This item is based on the seven-point scale: $7=$ extremely satisfied, $6=$ moderately satisfied, 5=slightly satisfied, 4=don't know/no opinion, 3=slightly dissatisfied, $2=$ moderately satisfied, and $1=$ extremely dissatisfied. The other items are based on the seven-point scale: $7=$ strongly agree, $6=$ moderately agree, $5=$ slightly agree, $4=$ don't know/no opinion, $3=$ slightly disagree, $2=$ moderately disagree, and $1=$ strongly disagree. 
( $r c$ ) Indicates a reverse coded question. These items were asked in a "negative" way in the survey, but they are presented in this table in an opposite (positive) direction to facilitate response comparison across items.

For the first measure, overall satisfaction, subjects rated the two online units they completed separately in the survey. Since statistical tests later revealed no significant differences across the units on this measure, for clarity and simplicity, the first item in Table 1 shows the pooled satisfaction ratings for both online units.

To minimize response bias, some survey questions were stated negatively. For example, in the survey, the fifth item in Table 1 was worded, "Completing the online units took more time and effort than it was worth," and the sixth item read, "Questions asked in the online units were too difficult." For reporting and analysis purposes, these items were reverse-coded and stated in a positive direction in Table 1 to allow easier comparison to the other responses. Thus, the reported averages for the fifth item (which was 2.18 on the seven-point scale) indicates that on average, participants agreed that the online experience "took more time and effort than it was worth."

Participants also rated the online learning units on several specific measures using a five-point scale, ranging from 5 for "excellent" to 1 for "extremely unsatisfactory." Again, while the two online units were rated separately on these dimensions, statistical tests revealed no significant differences across the units so Table 2 shows the pooled results of the ratings for both units.

Table 2. Ratings of Specific Learning Unit Dimensions

Ease of use

Clarity of information

Degree of interaction with user

Interesting

Useful

\begin{tabular}{cc} 
Mean & SD \\
\hline 3.37 & 1.01 \\
3.69 & 0.84 \\
3.54 & 0.97 \\
2.70 & 1.09 \\
3.24 & 1.00
\end{tabular}

In open-ended responses, participants expressed what they considered were the strengths of the online learning units. Overall, students responded favorably to the simulations (the ability to apply concepts to realistic problem-solving situations) and to the quality of the content. Students also spoke positively about the flexibility and convenience of the online material, the ease of use, the organization of the units, and the opportunity to gain experience in a new (online) environment. One participant commented, "The simulations are a valuable tool to gain experience with realistic environments." Another observed, "I liked the simulations because they allowed you to work through situations in a hands-on environment." Still another said, "It gives you another way to learn instead of reading from a book." 
The open-ended responses also suggest some problems and limitations of the experience. One of the most commonly reported content-related issues raised concerned the inclusion of simulations in the learning units, which, interestingly, was the most frequently mentioned benefit. Students were also frustrated with some of the technical issues-especially the losing of previously completed and saved work, which was inaccessible later. Overwhelmingly, the most commonly reported complaint was the length of the assignment. Many students said that the online units were too long and required too much time. One student commented, "Make the assignment shorter. The units were real time consuming." Another said that assigning "one online course probably would have been enough."

The classroom portion of the blended learning approach was also evaluated in terms of both "quantity" and "quality." Most students (94 percent) indicated that the amount of time devoted to class discussion of the learning units "was just about right."

\section{CONCLUSION}

Overall, the results of this study are mixed regarding the use of blended learning in the selected course. Although participants mentioned benefits of the online units in the open-ended responses - the most commonly mentioned benefits focused on the use of simulations to apply concepts to problem-solving situations along with the content and quality of the information presented - the overall evaluation of the units was lower than expected. The biggest issue that emerged in terms of user dissatisfaction involved the completion time, with more than 30 percent of participants commenting that the online units required too much time. On average, users needed nearly eight hours to finish the two learning units in their entirety, and this appears to be a greater investment of time than most students were willing to make, at least in a required (nonelective) course. It is likely that students' perceptions of this experience would have been more favorable if shorter online units were utilized or if only one of the two learning units had been required. This research outcome suggests that other educators who employ blended learning may want to select smaller segments of online courses spread over time rather than require entire courses that take several hours at a time.

In addition, none of the students had completed an online course at the MVU site before, and only 15 percent had ever completed any online course or learning activity. A growing body of research suggests that computer users' prior experience with technology affects their attitudes about technology in general $[6,11]$. The greater the amount of experience users have with technology, the higher levels of reported of users' satisfaction in learning to use new technology $[10,12]$. The participants' lack of any previous experience in e-learning may have led in part to the relative low satisfaction rating with the experience.

One prospect for future research is to compare student learning outcomes between classes using a blended learning approach versus those using traditional instruction. Another possibility is to examine user perceptions of blended learning where the online learning units are considerably shorter in length than those employed in this study. This approach would likely reduce the "fatigue factor" apparently experienced by some participants and result in greater user satisfaction. Additionally, research could explore which types of e-learning components- 
synchronous chat, asynchronous discussion postings, email, simulations, and so forth-are most effective in terms of learner satisfaction and in achieving desired student learning outcomes.

Furthermore, as students become more experienced in online instruction, their attitudes toward elearning and blended approaches may change. Complementary research can explore issues of familiarity and technical skill related to successful e-learning experiences. Overall, further research will likely yield additional insight to educators and trainers about where, when, and how to apply blended learning most effectively to meet the evolving needs of individuals both in school and in the workplace.

\section{REFERENCES}

1. Cole, M. S., Field, H. S. \& Harris, S. G. (2004). Student learning motivation and psychological hardiness: Interactive effects on students' reactions to a management class. Academy of Management Learning \& Education, 3(1), 64-85.

2. Davis, J. (2000). Traditional vs. online learning: It's not an either/or proposition. Employment Relations Today, 27(1), 47-60.

3. Hackman, J. R., ed. (1990). Groups that work (and those that don't). San Francisco: JosseyBass.

4. Hara, N. \& Kling, R. (2000). Students' distress with a web-based distance education course: An ethnographic study of participants' experiences. Information, Communication and Society, 3(4), 557-579.

5. Haugen, S., LaBarre, J. \& Melrose, J. (2001). Online course delivery: Issues and challenges. Issues in Information Systems, 2, 127-131.

6. Martins, L. L. \& Kellermanns, F. W. (2004). A model of business school students' acceptance of a web-based course management system. Academy of Management Learning \& Education, 3(1), 7-39.

7. Miller, R.A. \& Luse, D.W. (2004). Advancing the IS curricula: The identification of important communication skills needed by IS staff during systems development. Journal of Informational Technology Education, 3, 117-131.

8. O’Neill, K., Singh, G. \& O'Donoghue, J. (2004). Implementing elearning programmes for higher education: A review of the literature. Journal of Informational Technology Education, 3, 313-323.

9. Serwatka, J. (2003). Assessment in on-line CIS courses. Journal of Computer Information Systems, 43(3), 16-20.

10. Simmers, C. A. \& Anandarajan, M. (2001). User satisfaction in the Internet-anchored workplace: An exploratory study. Journal of Information Technology, Theory, and Application, 3(5), 39-62.

11. Stoel, L. \& Lee, K. H.. (2003). Modeling the effect of experience on student acceptance of Web-based courseware. Internet Research, 13(5), 364-374.

12. Volery, T. \& Lord, D. (2000). Critical success factors in online education. The International Journal of Education Management, 14(5), 216-223.

13. Watson, W. Kumar, E., K. \& Michaelsen, L. K. (1993). Cultural diversity's impact on interaction process and performance: Comparing homogenous and diverse task groups. Academy of Management Journal, 36, 590-602.

14. Ward, J. \& LaBranche, G. (2003). Blended learning: The convergence of e-learning and meetings. Franchising World, 35(4), 22-23. 